\title{
A Case Report-Non Extraction Treatment of Class II division 1Malocclusion with Excessive Overjet and Traumatic Bite
}

\author{
Naim MA ${ }^{1}$ BDS, MPH, Nahar L $^{2}$ BDS, FCPS, Islam S $^{3}$ BDS, DDS, Sultana $\mathrm{N}^{4}$ BDS, FCPS, \\ Nasrin $T^{5}$ BDS, FCPS and Hassan GS ${ }^{6}$ BDS, PhD
}

\begin{abstract}
In our orthodontic practice we have seen a recent spurt of increasing numbers of young adults who desire cost effective, non surgical correction of malocclusion and accept dental camouflage as a treatment option to mask the skeletal discrepancy. Usually over $10 \mathrm{~mm}$ overjet with traumatic bite is very difficult to treat without extraction; therefore this case is handling so carefully that the upper central incisors cannot loose or dead because of excessive force. In this case patient growth is complete and therefore the only option is fixed orthodontic treatment. So here the challenge is reduction of overjet and correction of traumatic bite without any extraction and is careful to save the tooth vitality. Following treatment marked improvement in patient's smile, facial profile and lip competence were achieved and there was a remarkable increase in the patient's confidence and quality of life.
\end{abstract}

\section{Key Words : Overjet, Extraction, Traumatic bite, tooth vitality.}

\section{INTRODUCTION}

Well aligned teeth not only contribute to the health of the oral cavity and the stomatognathic system, but they also influence the personality of the individual. A malocclusion compromises the health of the oral tissues and it can also lead to psychological and social problems. ${ }^{1}$ Over the last decade, increasing numbers of adults have become aware of orthodontic treatment and are demanding high quality treatment, in the shortest possible time with increased efficiency and reduced costs. ${ }^{2}$ The classical features of the class II, div 1 malocclusion include a mild to severe class II skeletal base with an Angles class II molar relation and class II canine and incisor relations, proclined maxillary incisors and an increased overjet and it generally has a convex profile with incompetent lips.1With all the classical feature the patient has class I molar \& canine relation. Treatment of an adult Class II patient requires careful diagnosis and a treatment plan involving esthetic, occlusal, and functional considerations. ${ }^{3}$ Ideally, the ability to identify specific abnomalities should lead to elimination of a malocclusion by normalization of the defective structures. In many situations, however, diagnosis is not matched by comparable differential treatment objectives and procedures. This problem is particularly evident in the correction of Class II malocclusions of skeletal origin in a non-growing patient. Class II malocclusion can be treated by several means, according to the characteristics associated with the problem, such as anteroposterior discrepancy, age, and patient compliance. ${ }^{4}$ On the other hand, correction of Class II malocclusions in nongrowing patients usually includes orthognathic surgery or selective removal of permanent teeth, with subsequent dental camouflage to mask the skeletal discrepancy. The indications for extractions in orthodontic practice have historically been controversial. $5,6,7$

This case report presents one such case of a 21 year old non-growing female, having Class I molar \& canine relation with class II division I incisor relation, an overjet of $10 \mathrm{~mm}$ with spacing of upper anterior segment. As there sufficient space was present camouflage treatment with nonextraction was considered acceptable.

\section{CASE DESCRIPTION}

The patient is a 21years old women came from Mymensing reported to BSMMU orthodontic department with the chief complain of aesthetic problem with spacing and proclination of anterior teeth, she is also depress about her smile and try to mask it. Her family worried and came Dhaka with the hope to change her life. Extra oral examination revealed a mesocephalic symmetrical face, convex hard and soft tissue profile and an acute nasolabial angle. The patient showed a good range of mandibular movements and no TMJ symptoms. Intra oral examination revealed that the patient has class I molar and canine relation. Incisors are class II division 1 with Traumatic bite and overjet is almost $10 \mathrm{~mm}$ in central incisors and $7 \mathrm{~mm}$ in lateral incisors. Traumatic over bite of $9 \mathrm{~mm}$ and associated palatal impingement of the lower incisors present. Spacing is present in upper anterior teeth. There is slight rotation of lower lateral incisors and also

\footnotetext{
${ }^{1}$ Dr. Mir Abu Naim, FCPS( Part II ) Department of Orthodontics,Faculty of Dentistry, BSMMU, ${ }^{2}$ Dr. Luthfun Nahar, Assistant professor, University Dental College \& Hospital , Dhaka. ${ }^{3}$ Dr. Shahidul Islam, Assistant professor, University Dental College \& Hospital, Dhaka. ${ }^{4}$ Dr.Naznin Sultana, Assistant Dental Surgeon, Bagmara Upojela, Rajshahi. ${ }^{5}$ Dr Dr. Tawhida Nasrin, Asst. Prof. \& Head, Dept. of Orthodontics, Update Dental College, Dhaka and ${ }^{6}$ Dr. Gazi Shamim Hassan,Chairman, Department of Orthodontics, Faculty of Dentistry, BSMMU, Dhaka.
} 
impression of upper anterior teeth present in inner portion of upper lip ( fig 1).

Panoramic radiograph shows right lower central incisor root is short. There is no other pathological finding(fig 2). Cephalometric examination revealed Class II skeletal relation with severe maxillary incisor proclination with horizontal growth pattern. (Fig 3) Our treatment objective focused on the chief complaint of the patient, and the treatment plan was individualized based on the specific treatment goals.
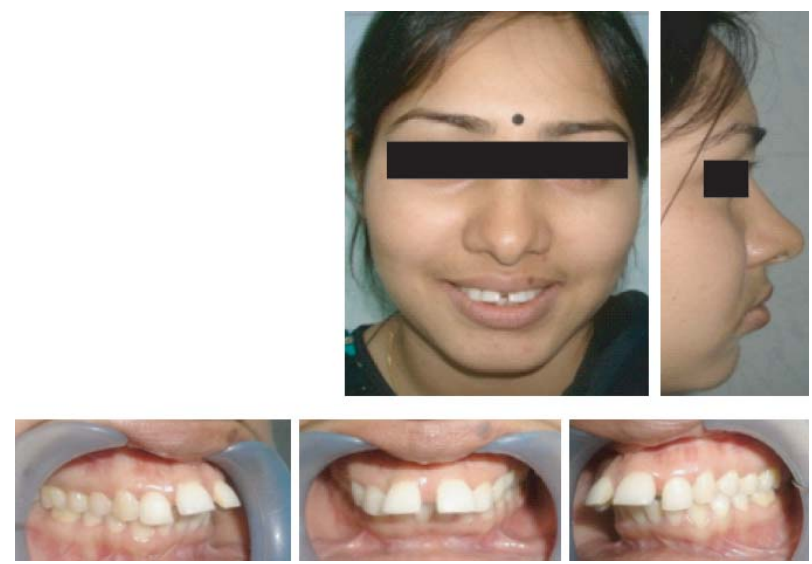

Figure 1: Pretreatment Intra \& Extra oral photographs

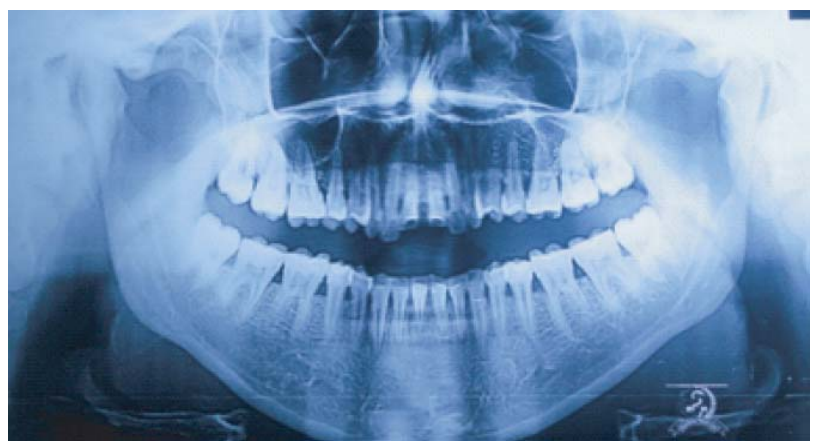

Fig 2: Pre-treatment Orthopentamogram

\section{TREATMENT GOAL}

- Obtaining a good facial balance

- Obtaining an optimal static and a functional occlusion and stability of the treatment results.

\section{TREATMENT OBJECTIVES}

The treatment objectives which would lead to an overall improvement of the hard and soft-tissue profile and the facial aesthetics are:

- To correct the upper incisors proclination

- To achieve an ideal overjet and over bite

- Correct the anteroposterior relationship.

- Improve the profile and facial esthetics.

\section{TREATMENT PLAN}

. Leveling and alignment of upper \& lower arches

. Close the spaces between upper Incisors

- Correction of deep overbite

. Upper arch contraction

. Arch co-ordination

. Residual space closer

. Finishing

. Retention

\section{BIOMECHANICS:}

Treatment started with a fixed appliance in the upper and lower arches. The first molars were banded and the maxillary and mandibular teeth were bonded from premolar to premolar with a $0.018 \times 0.025$ standard edgewise brackets. Initial leveling was accomplished with the use of multiloop arch wire of 0.014 " SS wire with stop loops and tip back and toe-in anchorage bends. Extreme care was taken to align upper incisors very slowly over 4-5 months. After initial leveling the incisors are apposition very slowly by loops and power chain with 0.016 " SS wire over 3 months. Then anterior retraction was done by rectangular $(0.017 \mathrm{X} 0.025$ inch) Stainless Steel archwire with "V" loops with proper control of third order bend (Torque )over 6 months. After anterior retraction, up and down elastic was given for 3 months. Final settling of occlusion was done with proper interdigitation, inclination, angulation, ideal overjet and overbite. After 20 months (from the time of placement of appliances) all teeth were aligned, \& satisfactory interdigitation was achieved, following which the case was debonded and fixed upper and lower lingual bonded retainer was given.

Fig 4: Post treatment Extra oral photographs
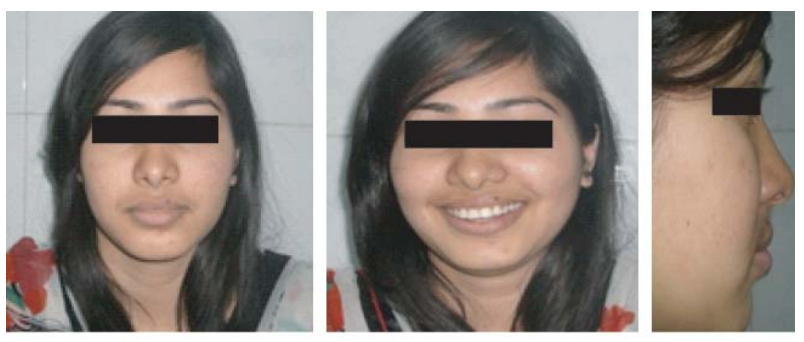

Fig 5: Post treatment Intra oral photographs
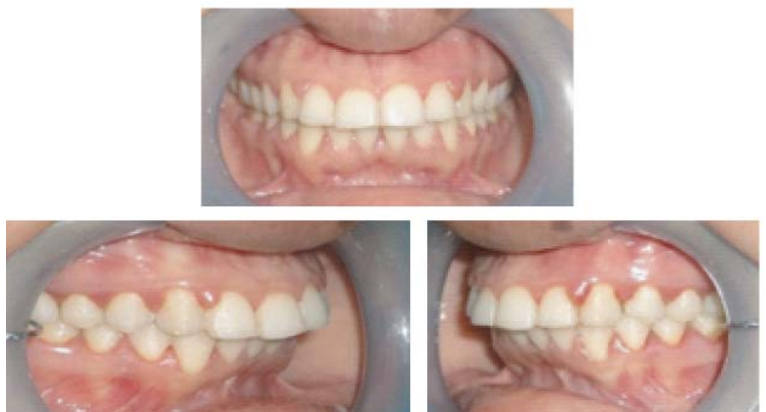


\section{RESULT}

the overall end result was satisfactory and describe below:

1. Dental changes: The arches are well aliened and normal overjet and overbite are achieved.

2. Profile changes: Initially her profile was convex and it's became straight after treatment.

3. Soft Tissue and smile changes: She is beautiful but her smile turns all beauties in dark shadow. So she tried to hide her smile always before treatment but now she looks gorgeous with her smile. Here soft tissue change was also achieved.

4. Cephalometric changes: Her chephalometric analysis show some changes after treatment.

\begin{tabular}{|c|c|c|c|}
\hline & Variable & Pre-treatment & $\begin{array}{l}\text { Post- } \\
\text { trantmant }\end{array}$ \\
\hline \multirow[t]{4}{*}{ Skeletal } & SNA & $86^{\circ}$ & $81^{\circ}$ \\
\hline & SNB & $78^{\circ}$ & $78^{\circ}$ \\
\hline & ANB & $8^{\circ}$ & $3^{\circ}$ \\
\hline & GoGn-SN & $32^{\circ}$ & $22^{\circ}$ \\
\hline \multirow[t]{5}{*}{ Dental } & I T1_-SN & $175^{\circ}$ & $114^{\circ}$ \\
\hline & $\mathrm{U} 1-\mathrm{NA}$ & $40^{\circ} / 8 \mathrm{~mm}$ & $33^{\circ} / 11 \mathrm{~mm}$ \\
\hline & $\mathrm{L} 1-\mathrm{NB}$ & $27^{\circ} / 9 \mathrm{~mm}$ & $37^{\circ} / 11 \mathrm{~mm}$ \\
\hline & IMPA & $85^{\circ}$ & $115^{\circ}$ \\
\hline & Overiet & $15 \mathrm{~mm}$ & $3.5 \mathrm{~mm}$ \\
\hline \multirow[t]{3}{*}{$\begin{array}{l}\text { Soft- } \\
\text { tissue }\end{array}$} & $\begin{array}{l}\text { Nasolabial } \\
\text { snoln }\end{array}$ & $78^{\circ}$ & $110^{\circ}$ \\
\hline & $\begin{array}{l}\text { U lip-S } \\
\text { lins }\end{array}$ & $5 \mathrm{~mm}$ & $\begin{array}{l}0^{\circ} \text { (Just } \\
\text { tnumhino) }\end{array}$ \\
\hline & L lip-S & $6 \mathrm{~mm}$ & $3 \mathrm{~mm}$ \\
\hline
\end{tabular}

5. Patient and parent psychological changes: There is very satisfactory physiological change achieved. According to patient her life is changed with this treatment.

\section{DISCUSSION}

The orthodontic treatment goals usually include obtaining a good facial balance and an optimal static and functional occlusion and stability of the treatment results. ${ }^{8,9}$ Whenever possible, all should be attained. Here the patient had improved smile and profile after orthodontic treatment. Lips were competent and lower lip controlled upper incisors successfully, which is very important for incisor stability. Upper incisors were retracted to achieve normal incisor inclinations, overjet and overbite. The case was successfully managed by contemporary orthodontic technique with intra oral anchorage incorporated in archwire.

\section{CONCLUSION}

Treatment time was 20 months .Patients had improved smile \& Profile. The correction of the malocclusion was achieved, with a significant improvement in the patient aesthetics and self-esteem. The patient was very satisfied with the result of the treatment.

\section{REFERENCES}

1 Naragond A,1 Kenganal S,2 Sagarkar R,3 and Sugaradday.Orthodontic Camouflage Treatment in an Adult Patient with a Class II, Division 1 Malocclusion - A Case Report, J Clin Diagn Res. 2013 Feb; 7(2): 395-400.

2. Khan RS, Horrocks EN. A study of adult orthodontic patients and their treatment. Br J Orthod,18(3):183-194; 1991.

3. Kuhlberg, A. and Glynn, E.: Treatment planning considerations for adult patients, Dent.Clin. N. Am. 41:17-28; 1997.

4. Salzmann JA. Practice of orthodontics. Philadelphia: J. B. Lippincott Company; p. 701-24;1966.

5. Case C S. The question of extraction in orthodontia. American Journal of Orthodontics, 50: 660-691; 1964.

6. Case C S. The extraction debate of 1911 by Case, Dewey, and Cryer. Discussion of Case: the question of extraction in orthodontia. American Journal of Orthodontics, 50: 900-912; 1964.

7. Tweed C. Indications for the extraction of teeth in orthodontic procedure. American Journal of Orthodontics 30: 405-428; 1944.

8.Bishara S, Hession T, Peterson L. Longitudinal soft-tissue profile changes: a study of three analyses. Am J Orthod. 1985;88:209-23. [PubMed]

9. Alexander RG, Sinclair PM, Goates LJ. Differetial diagnosis and treatment planning for adult nonsurgical orthodontic patient. Am J Orthod. 1986;89:95-112. [PubMed]

Correspodence

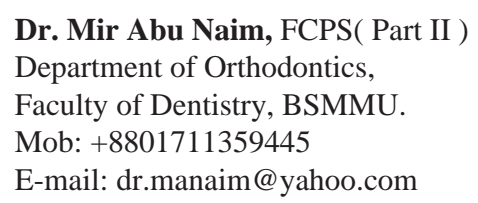

